\title{
Co-stimulation of cultured peripheral blood mononuclear cells from intrinsic asthmatics with exogenous recombinant IL-6 produce high levels of IL-4-dependent IgE
}

\author{
I.M. Sánchez-Guerrero*, N. Herrero**, M. Muro**, R.P. Vegara**, \\ M. Campos*, A.M. García-Alonso**, M. Rocío Álvarez**
}

\begin{abstract}
Co-stimulation of cultured peripheral blood mononuclear cells from intrinsic asthmatics with exogenous recombinant IL-6 produce high levels of IL-4-dependent IgE. I.M. Sánchez-Guerrero, N. Herrero, M. Muro, R.P. Vegara, M. Campos, A.M. GarcíaAlonso, M. Rocío Álvarez. C ERS Journals Ltd 1997.

ABSTRACT: Asthma is an inflammatory airway disorder, traditionally subdivided into extrinsic, immunoglobulin $\mathrm{E}$ (IgE)-mediated, and intrinsic asthma of unknown aetiology. IgE synthesis requires contact between $T$ - and B-cells and a signal provided by interleukin (IL)-4, which can be modulated by IL-6. The objective of this study was to evaluate the effects of IL-4 and IL-6 on total IgE synthesis by peripheral blood mononuclear cells from intrinsic and extrinsic asthmatics.

Peripheral blood mononuclear cells from intrinsic and extrinsic asthmatic patients and from healthy subjects were cultured and stimulated with pokeweed mitogen, recombinant IL-4 and IL-6. The IgE level in serum and supernatants was measured by an enzyme-linked immunoassay.

Serum IgE was significantly lower in intrinsic asthma than in extrinsic asthma, but significantly higher than in control subjects. IgE production by cultured mononuclear cells from extrinsic asthmatics was not modified after exogenous IL-4 and IL-6 addition. However, intrinsic asthmatics showed enhancement of IgE synthesis in response to IL-4 stimulation, reaching a threefold increase of the spontaneous IgE values, when simultaneous recombinant IL-4 plus IL-6 stimulus was used.

Our results indicate that exogenous recombinant interleukin-6 can significantly upregulate the interleukin-4-dependent immunoglobulin $\mathbf{E}$ synthesis in intrinsic asthma. This suggests that immunoglobulin $E$ could also play a role in the pathogenesis of intrinsic asthma, in which an interleukin-6 threshold would be critical. Eur Respir J 1997; 10: 2091-2096.
\end{abstract}

*Allergy Unit, Hospital Rafael Méndez, **Immunology Section, University Hospital Virgen de la Arrixaca, and +Biostatistics Unit, Medical School Murcia University, Murcia, Spain.

Correspondence: I.M. Sánchez-Guerrero Ricardo Gil 26, $2^{\circ} \mathrm{B}$

30002 Murcia

Spain

Keywords: Extrinsic asthma

immunoglobulin $\mathrm{E}$

interleukin-4

interleukin-6

intrinsic asthma

mononuclear cells

Received: August 121996

Accepted after revision May 111997

This work was supported by the Sociedad Española de Alergología e Immunología Clínica
One of the most challenging problems in all developed countries is the increasing number of patients with asthma. Bronchial asthma is a chronic inflammatory disease of the airways characterized by infiltration of inflammatory cells [1-4]. Although the precise immune features of the airway inflammation in asthma have not so far been well defined, the examination of biological activities shows that various types of cells are involved. Among them, activated T-cells can regulate immunoglobulin $(\mathrm{Ig}) \mathrm{E}$ production by B-cells in extrinsic asthma [5] through direct contact and by release of cytokines, thus providing the appropriate basis for immunoglobulin production and direct isotype switching. However, limited information is available on the immune mechanisms of intrinsic asthma.

Interleukin (IL)-6 is a cytokine, with a wide range of biological activities, produced by many different cell types, including tumoral cells [6-9]. It is involved in the regulation of inflammatory responses [10-13], and plays a critical role in the modulation of immune responses. The B-cell response is regulated by different factors. IL-4 acts in the early B-cell activation to stimulate proliferation and heavy chain isotype switching to $\mathrm{IgG}$ and IgE, while IL-6 is a late-acting differentiation factor for human activated B-cells to become plasma cells $[14,15]$. IgM, IgG and $\operatorname{IgA}$ production by pokeweed mitogen (PWM)-stimulated peripheral blood mononuclear cells (PBMCs) is also reported to be IL-6-dependent $[14,16,17]$.

In recent years, IgE synthesis by B-cells has been extensively studied and is now known to require at least two signals [18]. The first signal is provided by a physical contact between B- and T-cells and the second is delivered by IL-4, which is IgE-isotype-specific. In addition, it has been reported that IL-6 can enhance IL-4induced IgE synthesis [19-22], and that the presence of IL-2 is also required to produce an optimal humoral response [16, 23].

In order to investigate whether intrinsic asthmatic patients are able to produce high quantities of $\operatorname{IgE}$, we assessed the in vitro effect of human recombinant IL-4 (rhIL-4) and IL-6 (rhIL-6) on IgE production by PBMCs from such patients as compared to extrinsic asthmatics and healthy controls. The results of the experiments in this study suggest that IgE may also be involved in the immunological processes of intrinsic asthma. 


\section{Materials and methods}

\section{Study subjects}

Peripheral blood samples were obtained from 57 nonsmoking asthmatics, selected according to the definition of the American Thoracic Society on the basis of clinical symptoms (history of wheezing, chest tightness, and/or shortness of breath relieved by an inhaled $\beta$ agonist), physical examination and pulmonary function tests, demonstrating normal results or reversible airway obstruction, manifested by a postbronchodilator increase in forced expiratory volume in one second (FEV1) $>15 \%$. The asthmatic subjects were assigned either to the extrinsic or intrinsic group. Extrinsic asthmatics had a positive history of a bronchoconstrictive response after allergen exposure and one or more positive skin-prick tests with common allergen extracts, such as house-dust mite, moulds, pollens and animal danders. Intrinsic asthmatics developed symptoms following respiratory tract infections, but had no history of allergen-induced bronchospasm and negative skin-prick tests.

No patient was in acute respiratory distress at the time of the study or had required treatment for an exacerbation with oral or intravenous corticosteroids in the previous 6 months. Medication used by asthmatics included inhaled $\beta$-agonists on an as-needed basis, which was withheld at least $12 \mathrm{~h}$ before blood sampling. None of the extrinsic asthmatics had ever received immunotherapy. Thirty healthy individuals with no history of atopy and negative skin-prick tests were used as controls. None of them had taken any medication in the previous 3 months. The characteristics of the patients are presented in table 1 .

\section{Study design}

The aim of the study was to evaluate differences in the total IgE level in serum from extrinsic and intrinsic asthmatic patients and controls. Changes in in vitro $\mathrm{IgE}$ synthesis by PBMCs upon stimulation with PWM, rhIL4 and rhIL-6 were also studied.

\section{Serum IgE measurement}

A modified isotype-specific enzyme-linked immunosorbent assay (ELISA) was performed, as described previously [24], to measure serum IgE in asthmatic patients and controls. Therefore, microtitre plates (Microwell MaxiSorp; Nunc, Roskilde, Denmark) were coated with $100 \mu \mathrm{L} \cdot$ well $^{-1}$ of mouse antihuman IgE monoclonal anti-

Table 1. - Characteristics of the subjects studied

\begin{tabular}{|c|c|c|c|}
\hline & $\begin{array}{l}\text { Extrinsic } \\
\text { asthma }\end{array}$ & $\begin{array}{l}\text { Intrinsic } \\
\text { asthma }\end{array}$ & Control \\
\hline ubjects $n$ & 30 & 27 & 30 \\
\hline Sex $M / F$ & $10 / 20$ & $13 / 14$ & $12 / 18$ \\
\hline Age $\mathrm{yrs}^{\ddagger}$ & $\begin{array}{c}29 \\
(12-40)\end{array}$ & $\begin{array}{c}42 \\
(35-60)\end{array}$ & $\begin{array}{c}33 \\
(22-47)\end{array}$ \\
\hline $\begin{array}{l}\geq 1 \text { positive skin-prick test } \\
\text { Serum IgE } \mathrm{ng} \cdot \mathrm{mL}^{-1 \#}\end{array}$ & $\begin{array}{c}30 \\
465 \pm 458\end{array}$ & $\begin{array}{c}0 \\
57 \pm 42\end{array}$ & $\begin{array}{c}0 \\
17 \pm 13\end{array}$ \\
\hline
\end{tabular}

$\$$ : mean, and range in parenthesis; \#: mean \pm SEM. M: male; F: female; IgE: immunoglobulin E. body (Dakoppats, Glostrup, Denmark) at 1/75 dilution in $0.1 \mathrm{M} \mathrm{NaHCO}_{3}$ buffer (pH 9.6) overnight at $4^{\circ} \mathrm{C}$. After washing, the wells were blocked with $100 \mu \mathrm{L} \cdot$ well $^{-1}$ of bovine serum albumin (BSA) $1 \%$ in phosphate-buffered saline (PBS) and incubated for $1 \mathrm{~h}$ at $37^{\circ} \mathrm{C}$. After further washing, $100 \mu \mathrm{L}$ of serum or $\operatorname{IgE}$ control was added in duplicate. The standard IgE used as control was purchased from Behringwerke AG (Marburg, Germany). Following a $24 \mathrm{~h}$ incubation at $4{ }^{\circ} \mathrm{C}$, the wells were washed another three times. Then $100 \mu \mathrm{L}$ of $1 /$ 3,000 diluted alkaline phosphatase-labelled goat polyclonal antihuman IgE (Caltag Laboratories, Burlingame, CA, USA) was used as a second antibody and incubated by shaking at room temperature for $2 \mathrm{~h}$. Subsequently, $100 \mu \mathrm{L}$ of p-nitrophenyl phosphate (Kallestad, Austin, TX, USA) substrate solution was added to the wells after three washes with PBS-Tween 20 0.5\%. Absorbance was read at $405 \mathrm{~nm}$ with an ELISA reader (Whittaker 2001, Salzburg, Austria). The detection limit of this ELISA was $9.6 \mathrm{ng} \cdot \mathrm{mL}^{-1}$ and its coefficient of variation $6.7 \%$.

\section{Cell preparation and culture}

A randomized sample of 10 subjects from each group investigated was further selected to analyse the $\operatorname{IgE}$ production in vitro. PBMCs from patients and controls were isolated from heparinized venous blood by Ficoll density gradient centrifugation (Lymphoprep; Nicomed Pharma, Oslo, Norway) as reported previously [25]. These cells were washed three times and resuspended in medium RPMI 1640 (M.A. Bioproducts, Walkersville, MD, USA), supplemented with $10 \%$ foetal calf serum (Flow Laboratories, Irvine, UK), and cultured in flat-bottomed microtitre plates (Costar Corp., Cambridge,

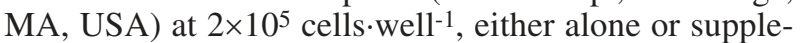
mented with PWM (Gibco Laboratories, Grant Island, NY, USA) at 1/100 (v/v), rhIL-4 (100 UI. $\left.\mathrm{mL}^{-1}\right)$ and rhIL-6 (20 UI. mL $\left.{ }^{-1}\right)$ (R \& D System, Abingdon, Oxon, $\mathrm{UK}$ ) or their combinations to induce IgE synthesis, as described previously [24]. The culture plates were incubated at $37^{\circ} \mathrm{C}$ in a humidified atmosphere of $5 \% \mathrm{CO}_{2}$ for 14 days to allow IgE isotype switching. Five replicates were performed on each point in every experiment. Nonstimulated supernatants were removed on days 3 and 14 of culture to determine the spontaneous production of $\mathrm{IgE}$, and the stimulated supernatants were recovered on day 14 to measure the induced $\mathrm{IgE}$ synthesis.

\section{Supernatant IgE measurement}

$\operatorname{IgE}$ levels in culture supernatants were determined by using a commercial low level IgE ELISA (The Binding Site, Birmingham, UK), following the manufacturer's technical guidelines. The coefficient of variation and the sensitivity of this $\operatorname{IgE}$ assay were $4.1 \%$ and 0.31 $\mathrm{ng} \cdot \mathrm{mL}^{-1}$, respectively.

\section{Statistical analysis}

Statistical analysis of serum IgE values was performed in the log-data by using a one-way analysis of variance (ANOVA) to compare differences between the 
three study groups. This analysis was completed by using a two-tailed, unpaired Student's t-test. Differences between mean values of supernatant determinations were analysed according to Student's t-test. Only pvalues below 0.05 were considered significant. Data are presented as mean \pm SEM.

\section{Results}

As expected, serum IgE values, measured by ELISA, were higher in patients with extrinsic asthma $(466 \pm 457.7$ $\left.\mathrm{ng} \cdot \mathrm{mL}^{-1}\right)$ than those observed in intrinsic asthma and healthy subjects. However, using this sensitive method, we observed that $\operatorname{IgE}$ values (mean \pm SEM) from intrinsic asthmatic patients $\left(57.3 \pm 42.3 \mathrm{ng} \cdot \mathrm{mL}^{-1}\right)$ were significan-

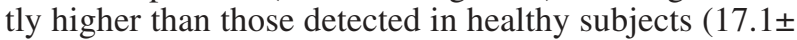
$\left.13.1 \mathrm{ng} \cdot \mathrm{mL}^{-1}\right)(\mathrm{p}<0.001)$. These data are presented in figure 1 .

Table 2 summarizes the measurements of basal serum $\mathrm{IgE}$ and spontaneous IgE release in culture supernatants from patients and controls. In cultures without mitogenic stimulus and prolonged for 14 days, the cells were not able to survive. Therefore, the supernatant IgE measurement showed values similar to those observed on day 3 of culture, which is considered to be a spontaneous IgE production. In fact, nonstimulated lymphocytes died in prolonged cultures. Consequently, IgE production did not increase. Therefore the data corresponding to spontaneous IgE production on day 3 are presented in figure 2 , which seems reasonable because IgE pro-

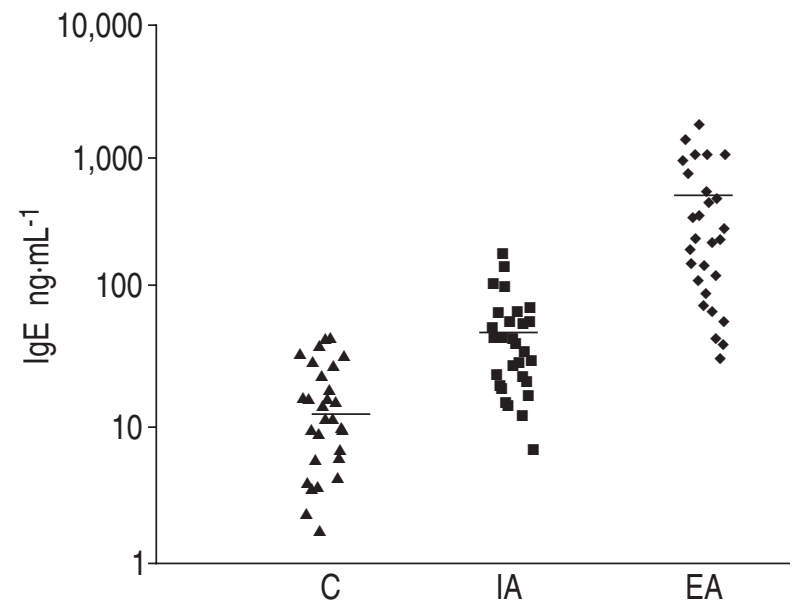

Fig. 1. - Distribution of serum $\operatorname{IgE}$ in the study groups. IgE was measured by ELISA in extrinsic asthmatic patients (EA), intrinsic asthmatic patients (IA) and control subjects (C). Data are presented in the log-rank. Horizontal bars represent mean values. IgE: immunoglobulin E; ELISA: enzyme-linked immunosorbent assay.

Table 2. - Serum IgE against spontaneous IgE in vitro production by the selected subjects from each group

\begin{tabular}{lccc}
\hline Group & Subjects & $\begin{array}{c}\text { Serum IgE } \\
\mathrm{ng} \cdot \mathrm{mL}^{-1}\end{array}$ & $\begin{array}{c}\text { Spontaneous IgE } \\
\text { production } \\
\mathrm{pg} \cdot \mathrm{mL}^{-1}\end{array}$ \\
\hline Extrinsic asthma & 10 & $202 \pm 94.4$ & $836.7 \pm 564.1$ \\
Intrinsic asthma & 10 & $44.9 \pm 23.2$ & $434.5 \pm 298.2$ \\
Control & 10 & $11.1 \pm 5.5$ & $530.0 \pm 119.4$
\end{tabular}

Data are presented as mean \pm SEM. Spontaneous IgE production was measured in supernatants recovered on day 3 of culture without stimulus. IgE: immunoglobulin E. duction in culture needs mitogenic stimulus and incubation for a period of 14 days [24]. The spontaneous nonstimulated IgE production appeared to be enhanced in the atopic patient group, as compared with intrinsic asthmatics and controls. In contrast to the results observed in serum, the lowest values of spontaneous IgE production corresponded to the intrinsic asthmatic group. However, none of these results reached statistical significance.

Measuring IgE levels in extrinsic asthmatic patients on day 14 , it was found that rhIL-4 either alone or in combination with rhIL-6 produced no consistent change in $\mathrm{IgE}$ response as compared to the values observed in the spontaneous or PWM-induced IgE production. Interestingly, in intrinsic asthmatic patients, IgE was markedly increased after stimulation with rhIL-4 $(\mathrm{p}<0.05)$, rising to values similar to those observed in extrinsic asthmatics. The addition both of rhIL- 4 and rhIL- 6 had a potentiating effect that resulted in an IgE level three times that of spontaneous production, which was significantly $(\mathrm{p}<0.02)$ higher than that observed in extrinsic asthmatics (fig. 2a).

All experiments with healthy subjects performed on day 14, under similar experimental conditions, yielded a strong enhancement of IgE levels in relation to their spontaneous production, when PBMCs were stimulated

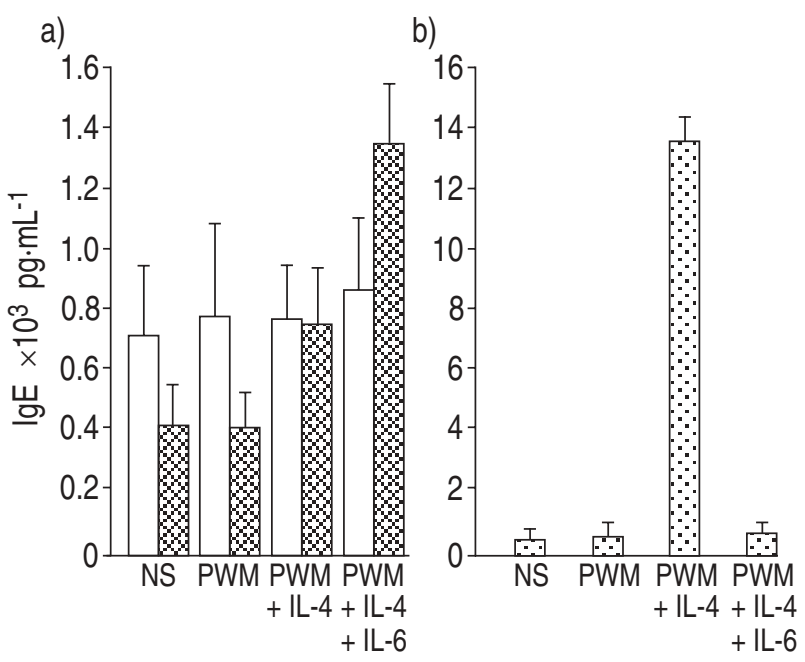

Fig. 2. - Influence of recombinant human interleukin (rhIL)-4 and rhIL- 6 on the IgE response elicited on day 14 by PWM-stimulated PBMCs. The supernatants were harvested on day 14 of the culture from: a) intrinsic asthmatic ( $)$ and extrinsic asthmatic $(\square)$ patients; and b) healthy control subjects. The production of total IgE was tested by ELISA. Results are expressed as mean+SEM. PWM: pokeweed mitogen; PBMCs: peripheral blood mononuclear cells; NS: nonstimulated; IL: interleukin. For further definitions see legend to figure 1.

Table 3. - Supernatant IgE levels in the study groups following the use of different stimuli

\begin{tabular}{lrcc}
\hline & Control & $\begin{array}{c}\text { Extrinsic } \\
\text { asthma }\end{array}$ & $\begin{array}{c}\text { Intrinsic } \\
\text { asthma }\end{array}$ \\
\hline Nonstimulated (day 3) & $530 \pm 231$ & $737 \pm 363$ & $434 \pm 123$ \\
Nonstimulated (day 14) & $512 \pm 249$ & $697 \pm 323$ & $401 \pm 203$ \\
Day 14 PWM & $593 \pm 377$ & $804 \pm 362$ & $427 \pm 109$ \\
Day 14 PWM + IL-4 & $13827 \pm 437$ & $850 \pm 229$ & $776 \pm 234$ \\
Day 14 PWM + IL-4 & $737 \pm 203$ & $890 \pm 314$ & $1378 \pm 327$
\end{tabular}

+ IL-6

PWM: pokeweed mitogen; IL: interleukin; IgE: immunoglobulin E. 
with rhIL-4 $(\mathrm{p}<0.0001)$. However, double stimulation with rhIL-4 and rhIL-6 in these subjects not only resulted in an enhancement of $\operatorname{IgE}$ synthesis but even reverted the rhIL-4-induced rise of IgE, whose values returned close to the basal values $(\mathrm{p}<0.05)$ (fig. $2 b)$. Supernatant $\mathrm{IgE}$ levels for each study group following the use of different stimuli are summarized in table 3 .

\section{Discussion}

Our study provides evidence that, upon simultaneous stimulation with PWM and exogenous rhIL-4 and rhIL6 , the PBMCs of intrinsic asthmatics can synthesize in vitro high levels of IgE, even greater than IgE production in extrinsic asthmatic patients. We were interested in these respiratory disorders because they share similar clinical manifestations, despite exhibiting different immunological characteristics. The mechanism responsible for this dichotomy remains unclear, but it would be tempting to hypothesize that an impaired helper Tcell function and a different lymphokine network could be involved in the pathogenesis of each type of asthma. A relative dominance of T-helper type-2 (Th2)-mediated responses has been reported for extrinsic asthma [5, 26], but it is unknown, so far, which pattern of mediators regulates intrinsic asthma.

The detection of a moderate increase of serum IgE levels in intrinsic asthmatic patients, as well as our previous finding that serum CD23 was enhanced in these subjects [27], supports the idea that the IgE system could also be implicated in this type of asthma, although via another regulatory pathway. Therefore, this work was focused on researching the in vitro production of $\mathrm{IgE}$ in both diseases, studying their behaviour under identical culture conditions.

MAGGi et al. [28] have reported that IL-6 potentiates the IL-4-induced IgE synthesis by B-cells in atopic patients, but our results showed that the amounts of $\operatorname{IgE}$ produced by PBMCs from atopic asthmatic patients either in the presence or absence of IL-6 did not differ significantly, even in the presence of exogenous rhIL4. Since it is known that B-cells from these patients are induced to switch to $\operatorname{IgE}$ production, the endogenous IL-4 may be enough to activate it. In addition, IL-6 can be synthesized not only by T-cells but also by activated monocytes and alveolar macrophages [14, 29]; thus, it is probable that the amount of endogenous IL-6 produced by atopic patients could be optimal, and exogenous addition of rhIL-6 and rhIL-4 would not enhance IgE production.

When PBMCs from intrinsic asthmatic patients were analysed, we observed that IgE production appeared to be conditioned by rhIL-4 and rhIL-6. It has been reported that IL-4, which induces IgE synthesis [18, 30-32], is decreased in intrinsic asthma [33]; hence, the exogenous addition of this interleukin could explain the fact that intrinsic asthmatics produced IgE in similar quantities to those produced by extrinsic asthmatics. Nevertheless, it was surprising that, when rhIL-6 and rhIL-4 were added simultaneously, the increase in the level of $\operatorname{IgE}$ in this group exceeded the production of $\operatorname{IgE}$ by atopic patients. These findings indicate that PBMCs from intrinsic asthmatic patients are able to lead to an $\mathrm{IgE}$ response, at least under in vitro conditions.
In the control group, exogenous rhIL-4 was able to induce a strong IgE response by PBMCs, which may be due to the effect exerted on resting B-cells to induce IL4 receptor and CD40-L expression. Moreover, exogenous IL-4 could lead to an immune deviation from uncommitted T-helper (Th0) phenotype to Th2, which increases the endogenous IL-4 production, resulting in IgE switching of the control subject lymphocytes. However, B-cells from extrinsic asthmatic patients would not be affected in this way, while intrinsic asthmatic patients, exhibiting slightly but significantly elevated serum $\operatorname{IgE}$ values, could represent an intermediate situation, where the degree of cell differentiation would allow an intermediate rhIL-4-induced IgE response. Although MAGGI et al. [28] reported that rhIL-6 had no effect on the synthesis of IgE by B-cells from nonatopic donors, we found that the supplementary rhIL-6 abrogated the IL-4-exogenous effect on IgE synthesis by PBMCs from healthy controls; but it should be taken into account that we used a different experimental system and PBMCs instead of isolated B-cells.

The impaired response to exogenous IL- 6 could be explained by several mechanisms. Firstly, it might be suggested that cells from intrinsic asthmatics were unable to release appropriate amounts of IL-6; but we are not convinced of this, because when IL-6 was measured in sera and culture supernatants, we found similar amounts of this cytokine in intrinsic and extrinsic asthmatic patients (data not shown). Secondly, as has recently been reported, the amplitude of the IL-6 response seems to be determined by the ratio of two subunits (gp80 and gp130) of the IL-6 receptor on the cell surface. Thus, if gp80 membrane expression was low, IL-6 could not induce appropriate responsiveness. Indeed, IL-6 induces gp130 subunit expression, which, in turn, determines the level of IL-6/gp80 binding on the membrane to induce transduction of specific signals [34]. Moreover, the unusual fact that IL-6 shows an agonistic behaviour with its receptor [35] could suggest that, in the presence of an excess of exogenous IL-6, gp130 receptor subunit expression could be induced on the cell surface, allowing the amplifying action of IL-6. Taking these considerations into account, it is quite reasonable to conclude that endogenous IL-6 levels in intrinsic asthmatic patients were restrictive to allow an adequate gp130 expression, which would be enhanced by exogenous addition of rhIL-6.

It is now well established that the regulatory events for $\operatorname{IgE}$ synthesis are triggered by the activation of CD4+ T-cells, which requires physical interaction between $\mathrm{T}$ - and B-cells involving the T-cell receptor complex and major histocompatibility complex class II molecules [36]. Once activated, T-helper cells express other essential surface molecules, which interact as ligand-receptor pairs, such as CD28-B7, CD21-CD23, and CD40-gp39 [37-39], providing a second signal by T-cell derived interleukins, particularly IL-4 and IL-6. In a murine model, HilberT et al. [40] examined the differential IL-6 requirements of primary and secondary antigen-specific B-cell response, and concluded that the antibody secretion of naive B-cells is entirely IL-6-dependent, while the antigen-primed B-cell responsiveness is essentially IL-6-independent. It has also been reported that IL-6 does not play a significant part in antibody 
responses to the influenza virus by human tonsillar mononuclear cells [41]. Considering these observations, we believe that in intrinsic asthmatic patients, rhIL-6 is likely to trigger T-helper cells to induce a subsequent signal necessary for the development of primary response, while this cytokine would not act in extrinsic asthmatic patients since they could only undergo a secondary response.

At the time of this study and on the basis of the information available, little is known about the possible participation of IgE in the pathogenesis of intrinsic asthma [42]. For the first time, this report demonstrates that PBMCs from intrinsic asthmatic patients, at least under the present experimental conditions, are able to exceed the in vitro production of $\mathrm{IgE}$ by extrinsic asthmatic patients. This finding suggests that in the in vivo microenvironment airway cells, such as monocytes, alveolar macrophages and bronchial epithelial cells, which can secrete increased local amounts of IL-6 [43], may act on B-cells delivering a strong in situ IgE response that is likely to be responsible for the clinical manifestations of intrinsic asthma.

In summary, our data provide circumstantial evidence that the peripheral blood B-lymphocytes from intrinsic asthmatics may cause a high immunoglobulin $\mathrm{E}$ response in the presence of appropriate amounts of interleukins. This fact, together with the reports of other authors [42], supports the idea that both types of asthma could be caused, at least in part, by a common immunological feature, possibly regulated via different pathways. This possibility has yet to be demonstrated by further investigations to analyse the regulatory T-cell cytokine network in more detail, since a better understanding of immunoglobulin $\mathrm{E}$ function and production in intrinsic asthma will open new ways for designing more rational approaches to the therapy of this disease.

Acknowledgement: The authors are indebted to A. Escudero for supplying some of the patients' blood samples.

\section{References}

1. Djukanovic R, Roche WR, Wilson JW, et al. Mucosal inflammation in asthma. Am Rev Respir Dis 1990; 142: 434-457.

2. Bentley AM, Maestrelli P, Saetta M, et al. Activated Tlymphocytes and eosinophils in the bronchial mucosa in isocyanate-induced asthma. J Allergy Clin Immunol 1992; 98: 821-829.

3. Bentley AM, Menz G, Storz CHR, et al. Identification of T-lymphocytes, macrophages, and activated eosinophils in the bronchial mucosa in intrinsic asthma. Am Rev Respir Dis 1992; 146: 500-506.

4. Ricci M, Rossi O, Bertoni M, Matucci A. The importance of Th2-like cells in pathogenesis of airway allergic inflammation. Clin Exp Allergy 1993; 23: 360-369.

5. Robinson DS, Hamid Q, Ying S, et al. Predominant Th2-like bronchoalveolar T-lymphocyte population in atopic asthma. N Engl J Med 1992; 326: 298-304.

6. Shimizu M, Hirano T, Ishibashi K, et al. Immortalization of BGDF (BCGFII)- and BCDF-producing T-cells by human T-cell leukemia virus (HTLV) and characterization of human BGDF (BCGFII). J Immunol 1985; 134: 1728-1733.
7. Hirano T, Yasukawa K, Harada H, et al. Complementary DNA for a novel human interleukin (BSF-2) that induces B-lymphocytes to produce immunoglobulin. Nature 1986; 324: 73-76.

8. Hirano T, Taga T, Yasukawa K, et al. Human B-cell differentiation factor defined by an antipeptide antibody and its possible role in autoantibody production. Proc Natl Acad Sci USA 1987; 84: 228-231.

9. Guerne P-A, Carson DA, Lotz M. IL-6 production by human articular chondrocytes. J Immunol 1990; 144: 499-505.

10. Gauldie J, Richards C, Harnish D, Landsdorp P, Baumann $H$. Interferon $\beta_{2}$ B-cell stimulatory factor type- 2 shares identity with monocyte-derived hepatocyte-stimulating factor and regulates the major acute phase protein response in liver cells. Proc Natl Acad Sci USA 1987; 84: 12511255.

11. Hack CE, De Groot ER, Felt-Bersna RJF, Nuijens JH, Strack Van Schijndel RJM, Eerenberg-Belmer AJM. Increased plasma levels of interleukin-6 in sepsis. Blood 1989; 74: 1704-1710.

12. Hirano T, Akira S, Taga T, Kishimoto T. Biological and clinical aspects of interleukin-6. Immunol Today 1990; 11: 443-449.

13. Mayer P, Geissler K, Valent P, Ceska M, Bettelheim P, Liehl E. Recombinant human interleukin-6 is a potent inducer of the acute phase response and elevates the blood platelets in nonhuman primates. Exp Hematol 1991; 19: 688-696.

14. Kishimoto T. The biology of interleukin-6. Blood 1989; 74: $1-10$

15. Herrod HG. Interleukins in immunologic and allergic diseases. Ann Allergy 1989; 63: 269-272.

16. Splawski JB, McAnally LM, Lipsky PE. IL-2 dependence of the promotion of human B-cell differentiation by IL-6 (BSF-2). J Immunol 1990; 144: 562-569.

17. Hirano T, Taga T, Yamasaki K, et al. A multifunctional cytokine (IL-6/BSF-2) and its receptor. Int Arch Allergy Appl Immunol 1989; 88: 29-33.

18. Vercelli D, Geha RS. Regulation of IgE synthesis in humans: a tale of two signals. J Allergy Clin Immunol 1991; 88: 285-295.

19. Vercelli D, Jabara HH, Arai K-I, Yokota T, Geha RS. Endogenous interleukin-6 plays an obligatory role in interleukin-4-dependent human $\operatorname{IgE}$ synthesis. Eur $J$ Immunol 1989; 19: 1419-1424.

20. Jabara HH, Ahern DJ, Vercelli D, Geha RS. Hydrocortisone and IL-4 induce IgE isotype switching in human B-cells. J Immunol 1991; 147: 1557-1560.

21. Gosset P, Tsicopoulos A, Wallaert B, Joseph M, Capron A, Tonnel A-B. Tumor necrosis factor-alpha and interleukin-6 production by human mononuclear phagocytes from allergic asthmatics after IgE-dependent stimulation. Am Rev Respir Dis 1992; 146: 768-774.

22. Pène J. Regulatory role of cytokines and CD23 in the human IgE antibody synthesis. Int Arch Allergy Appl Immunol 1989; 90: 32-40.

23. Smith SH, Shields JG, Callard RE. Human T-cellreplacing factor(s): a comparison of recombinant and purified human B-cell growth and differentiation factors. Eur J Immunol 1989; 19: 2045-2049.

24. Zhang K, Clark EA, Saxon A. CD40 stimulation provides an IFN- $\gamma$-independent and IL-4-dependent differentiation signal directly to human B-cells for $\mathrm{IgE}$ production. J Immunol 1991; 146: 1836-1842.

25. Boyüm A. Isolation of mononuclear cells and granulocytes from human blood: isolation of mononuclear cells 
by one centrifugation and sedimentation at $1 \mathrm{~g}$. Scand J Clin Lab Invest 1968; 21 (Suppl. 97): 77-82.

26. Kapsenberg ML, Wierenga EA, Bos JD, Jansen HM. Functional subsets of allergen-reactive human CD4+ Tcells. Immunol Today 1991; 12: 392-395.

27. Sánchez-Guerrero I, Albaladejo MD, García-Alonso AM, Muro M, Hernández J, Alvarez MR. Soluble CD23 (sCD23) serum levels and lymphocyte subpopulations in peripheral blood in rhinitis and extrinsic and intrinsic asthma. Allergy 1994; 49: 587-592.

28. Maggi E, Del Prete GF, Parronchi P, et al. Role for Tcells, IL-2 and IL-6 in the IL-4-dependent in vitro human IgE synthesis. Immunol 1989; 68: 300-306.

29. Gosset P, Tsicopoulos A, Wallaert B, et al. Increased secretion of tumor necrosis factor- $\alpha$ and interleukin- 6 by alveolar macrophages consecutive to the development of the late asthmatic reaction. J Allergy Clin Immunol 1991; 88: 561-571.

30. Pène $\mathrm{J}$, Rousset $\mathrm{F}$, Briére $\mathrm{F}$, et al. IgE production by human B-cells is induced by IL-4 and suppressed by interferon- $\gamma,-\alpha$ and prostaglandin $\mathrm{E}_{2}$. Proc Natl Acad Sci USA 1988; 85: 8166-8170.

31. Romagnani S. Regulation and deregulation of human IgE synthesis. Immunol Today 1990; 11: 316-321.

32. Romagnani S, Ricci M. Present views on the regulation of human IgE synthesis. ACI News 1990; 2: 192-196.

33. Walker C, Bode E, Boer L, Hansel TT, Blaser K, Virchow JC Jr. Allergic and nonallergic asthmatics have distinct patterns of T-cell activation and cytokine production in peripheral blood and bronchoalveolar lavage. Am Rev Respir Dis 1992; 146: 109-115.

34. Mackiewicz A, Schooltink H, Heinrich PC, Rose-John S. Complex of soluble human IL-6-receptor/IL-6 upregulates expression of acute phase proteins. J Immunol 1992; 149: 2021-2027.
35. Müllberg J, Schooltink H, Stoyan T, et al. The soluble interleukin-6 receptor is generated by shedding. Eur $J$ Immunol 1993; 23: 473-480.

36. Vercelli D, Habara HH, Arai KI, Geha RS. Induction of human IgE synthesis requires interleukin-4 and T/ $\mathrm{B}$-cell interactions involving the T-cell receptor/CD23 complex and MHC class II antigens. J Exp Med 1989; 169: 1295-1307.

37. Aubry JP, Pochon S, Graber P, Jansen KU, Bonnefoy JY. CD21 is a ligand for CD23 and regulates IgE production. Nature 1992; 358: 505-507.

38. Aubry JP, Shields JG, Jansen KU, Bonnefoy JY. A multiparameter flow cytometric method to study surface molecules involved in interactions between subpopulations of cells. J Immunol Methods 1993; 159: 161-171.

39. Marshall LS, Aruffo A, Ledbetter JA, Noelle RJ. The molecular basis for T-cell help in humoral immunity: CD40 and its ligand, gp 39. J Clin Immunol 1993; 13: 165-174.

40. Hilbert DM, Cancro MP, Scherle PA, et al. T-cell-derived IL-6 is differentially required for antigen-specific antibody secretion by primary and secondary B-cells. $J$ Immunol 1989; 143: 4019-4024.

41. Costelloe KE, Smith SH, Callard RE. Interleukin-6 is not required for antigen-specific antibody responses by human B-cells. Eur J Immunol 1993; 23: 984-987.

42. Burrows B, Martinez FD, Halonen M, Barbee RA, Cline MG. Association of asthma with serum IgE levels and skin-test reactivity to allergens. N Engl J Med 1989; 320: 271-277.

43. Marini M, Vittori E, Hollemborg J, Mattoli S. Expression of the potent inflammatory cytokines, granulocyte/ macrophage colony-stimulating factor and interleukin6 and interleukin-8, in bronchial epithelial cells of patients with asthma. J Allergy Clin Immunol 1992; 89: 1001-1009. 